\title{
Retinoic acid inhibits the fixation of initial transformational damage in X-irradiated Balb/3T3 mouse fibroblasts in vitro
}

\author{
Hans Peter Rutz ${ }^{1}$ and John B.Little ${ }^{2}$ \\ Harvard School of Public Health, Department of Cancer Biology, \\ 665 Huntington Avenue, Boston, MA 02115, USA \\ 'Present address: Laboratoire de Radiobiologie, Service de Radiothérapie, \\ Centre Hospitalier Universitaire Vaudois, CH-1011 Lausanne, Switzerland \\ ${ }^{2}$ To whom correspondence should be addressed
}

We have examined the effects of all-trans retinoic acid (RA) on confluent holding recovery (cell survival) and on the fixation of initial transformational damage expressed as the ultimate yield of transformed foci following X-irradiation of density-inhibited cultures of Balb/3T3 cells. Non-cytotoxic concentrations of RA suppressed both recovery of potentially lethal damage and neoplastic transformation in a dosedependent manner when added for $24 \mathrm{~h}$ during postirradiation confluent holding after a dose of $5 \mathrm{~Gy}$. At $100 \mu \mathrm{M}$, RA inhibited the fixation of initial transformational damage by $80 \%$. These findings are discussed in terms of the hypothesis that retinoids may allow a selective enhancement of the inactivation of certain irradiated tumor cells in vivo while reducing the risk of secondary malignancies in successfully treated patients.

\section{Introduction}

Vitamin A and certain of its natural and synthetic analogs, collectively called retinoids, are potent inhibitors of carcinogenesis at many tissue and organ sites in both rodents $(1-3)$ and humans $(4-6)$. They also inhibit chemically $(7-9)$ and radiationinduced $(10,11)$ transformation in vitro, as well as transformation by transfection with human oncogenes (12). The use of retinoids in cancer prevention has therefore become a promising field of investigation $(4-6)$. The mechanisms of this inhibition, however, are not yet fully understood.

Malignant transformation develops in two distinct phases: the first is the production and fixation of initial transformational damage as a heritable cellular property, and the second is the phenotypic expression of this damage as a morphologically altered cell (13). Several studies have reported effects of retinoids on cells in culture which result in a stabilization of the non-transformed phenotype; these include effects on cell growth, adhesion to the culture substrate, cell morphology, cytoskeleton, proteinphosphorylation, expression of cellular proto-oncogenes, expression of receptors, differentiation, membrane function, inhibition of the protein kinase $\mathrm{C}$ cascade system, and blocking of the $G_{0}$ to $G_{1}$ transition in the mitotic response of initiated cells to growth factors which act as endogenous promoters of transformation (14-23). However, little is known about effects of retinoids on cellular recovery mechanisms underlying the fixation of initial transformational damage.

Cellular recovery processes mitigate the cytotoxic (repair of potentially lethal damage or PLD* repair) and clastogenic (repair of chromosomal aberrations) effects of carcinogen exposure; they

*Abbreviations: PLD, potentially lethal damage; RA, all-trans retinoic acid are involved in the fixation of DNA sequence alterations resulting in mutants as well as in neoplastic transformation through processes leading to the fixation of initial transformational damage (24). Cellular repair can be studied in confluent holding recovery experiments with density-inhibited, confluent cultures of mammalian cells $(25,26)$.

In such experiments, DNA repair processes can act to remove damage in the absence of ongoing DNA replication. Subculture to low density at various times after exposure stimulates the initiation of DNA synthesis, allowing resumption of active traversal of the cell cycle. When confluent cultures are immediately subcultured to low density after exposure to radiation, a dose-dependent induction of effects such as cell killing, mutagenesis, transformation and chromosomal rearrangement occurs. These toxic effects are reduced when postirradiation recovery periods of $24 \mathrm{~h}$ or longer are allowed prior to subculture $(24-29)$. Such recovery has not been observed in certain repair-deficient cell strains $(30-32)$, suggesting the involvement of DNA repair in the confluent holding recovery phenomenon.

In the present investigation, we have examined effects of a $24 \mathrm{~h}$ post-irradiation exposure to all-trans retinoic acid (RA) on confluent holding recovery (PLD repair) and on the fixation of initial transformational damage expressed as the ultimate yield of transformed foci in Balb/3T3 mouse fibroblasts.

\section{Materials and methods}

Cells and culture conditions, irradiation, confluent holding

The Balb/3T3 cell system and the procedures for the maintenance of these cells, as well as the radiation source, have been described in detail elsewhere (33). The cells were grown in Eagle's minimum essential medium supplemented with $10 \%$ serum. This serum was Biocell VSP neonate calf serum lot no. 211200 for experiments I-III, Biocell VSP neonate bovine serum lot no. 36211A182 for experiment IV, and Gibco heat-inactivated calf serum, cat. no. 230-6170AJ for experiments V-VII.

All experiments were carried out with density-inhibited, confluent cultures. Three daily medium changes after reaching confluence allowed the cells to approach a steady state. They were irradiated in conditioned medium $24 \mathrm{~h}$ after the last medium change with a dose of $5 \mathrm{~Gy}$. Survival was determined by a routine colonyformation assay (33). The cloning efficiency in these experiments ranged from 83.5 to $97.5 \%$. Survival and the transformation frequency were determined immediately following irradiation. An additional set of similarly treated cultures was used to examine the effects of post-irradiation incubation with RA on confluent holding recovery and on the fixation of initial transformational damage.

RA, received from Sigma (cat. no. R-2625), was dissolved in ethanol (10 mM stock solution) and stored at $4^{\circ} \mathrm{C}$ in the dark. From this solution, RA was diluted into complete medium. The conditioned medium was removed immediately after irradiation and replaced with fresh medium containing various concentrations of RA up to $100 \mu \mathrm{M}$. After $24 \mathrm{~h}$, the cells were subcultured into medium without RA at low density (200 viable cells/dish) to determine survival and at a higher density (10000 viable cells/dish) for the transformation assay. The effect of a $24 \mathrm{~h}$ treatment with RA on the cloning efficiency of non-irradiated cultures was determined in a parallel set of dishes. The number of colonies with $>50$ viable appearing cells was scored after 8-10 days.

Transformation assay

Cell numbers were adjusted in each treatment group such that $\sim 10000$ viable (colony forming) cells from the same confluent cultures as those used to measure survival were seeded in each of 20-60 100-mm Lux Petri dishes. The nutrient medium was renewed on the third or fourth day after irradiation. In experiments 


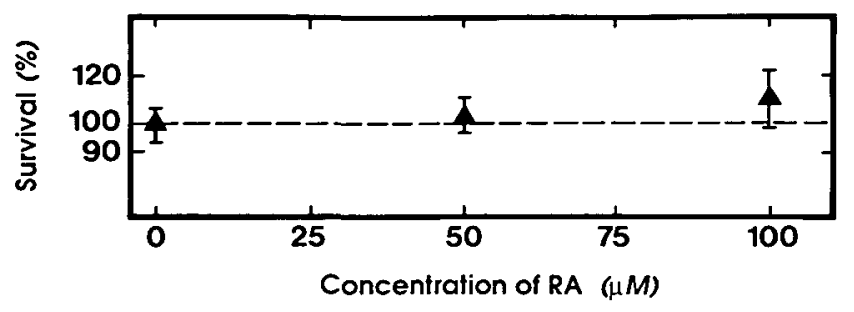

Fig. 1. Survival of density-inhibited, confluent cultures of Balb/3T3 mouse fibroblasts following a $24 \mathrm{~h}$ incubation with RA. Data points are the mean of three independent experiments. Error bars indicate one SD.

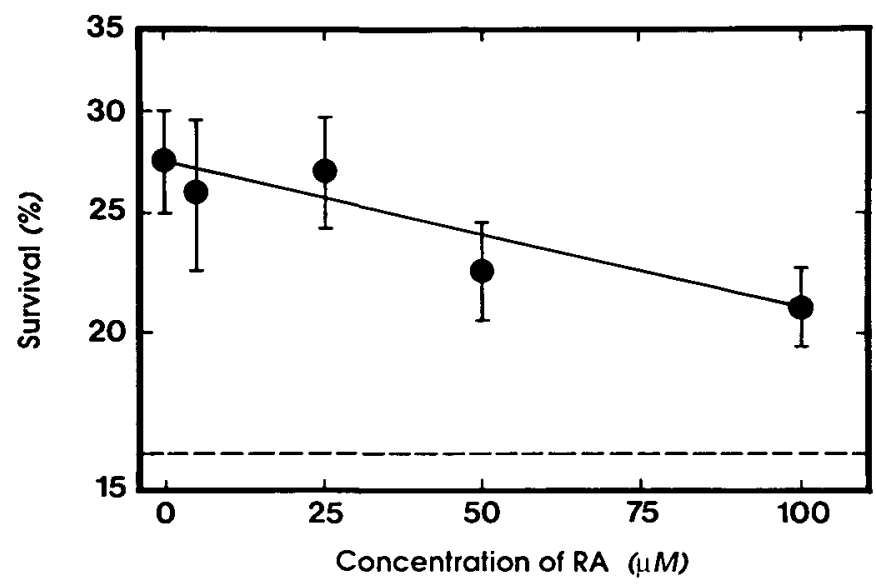

Fig. 2. Inhibitory effect of RA on confluent holding recovery in Balb/3T3 cells irradiated with a dose of $5 \mathrm{~Gy}$. RA was present only during the $24 \mathrm{~h}$ post-irradiation recovery period. Dashed line: survival of cells subcultured to low density immediately following irradiation. The data points were calculated from six independent experiments. Error bars indicate one SD.

I-III, the medium was subsequently changed every 10 days; in experiments IV-VII, twice each week. After 4 weeks, the cultures were fixed and stained. Transformed foci were scored as described by Kakunaga (34). Since previous transformation studies have shown that the number of foci appearing per dish is independent of the number of cells initially seeded $(33,35)$, the results are expressed in terms of the number of foci per dish (35).

Statistical analysis

For the estimation of the effects of RA on PLD repair and on survival of unirradiated Balb/3T3 cells, we calculated the mean \pm one SD from six (PLD repair) or three (RA toxicity) independent experiments. The effects of RA on the fixation of initial transformational damage were calculated from the fraction of dishes without foci of transformed cells arising from irradiated cells which were exposed to various concentrations of RA during $24 \mathrm{~h}$ of post-irradiation confluent holding. Statistical analysis was calculated as described by Han and Elkind (36) and Balcer-Kubiczek et al. (37). The data from experiments II - VII were pooled to calculate the transformation frequencies. The results of experiment I were excluded from this study because of an unusually high background frequency of transformation; foci of transformed cells appeared in 18 of 19 non-irradiated control dishes. These results (in terms of the actual number of foci per dish), however, were qualitatively similar to those of the other six experiments.

\section{Results}

\section{Effects of RA on confluent holding recovery}

Treatment of non-irradiated confluent cultures with RA alone for $24 \mathrm{~h}$ had no significant effect on survival for all concentrations studied (Figure 1). Figure 2 shows the inhibitory effect of RA on confluent holding recovery. Survival of cells subcultured immediately after irradiation (initial survival) was $16 \pm 3 \%$ (dotted line in Figure 2). During the $24 \mathrm{~h}$ confluent holding period, survival increased to $27.5 \pm 2.5 \%$ in the absence of $R A$, reflecting the repair of PLD. RA suppressed the recovery in a

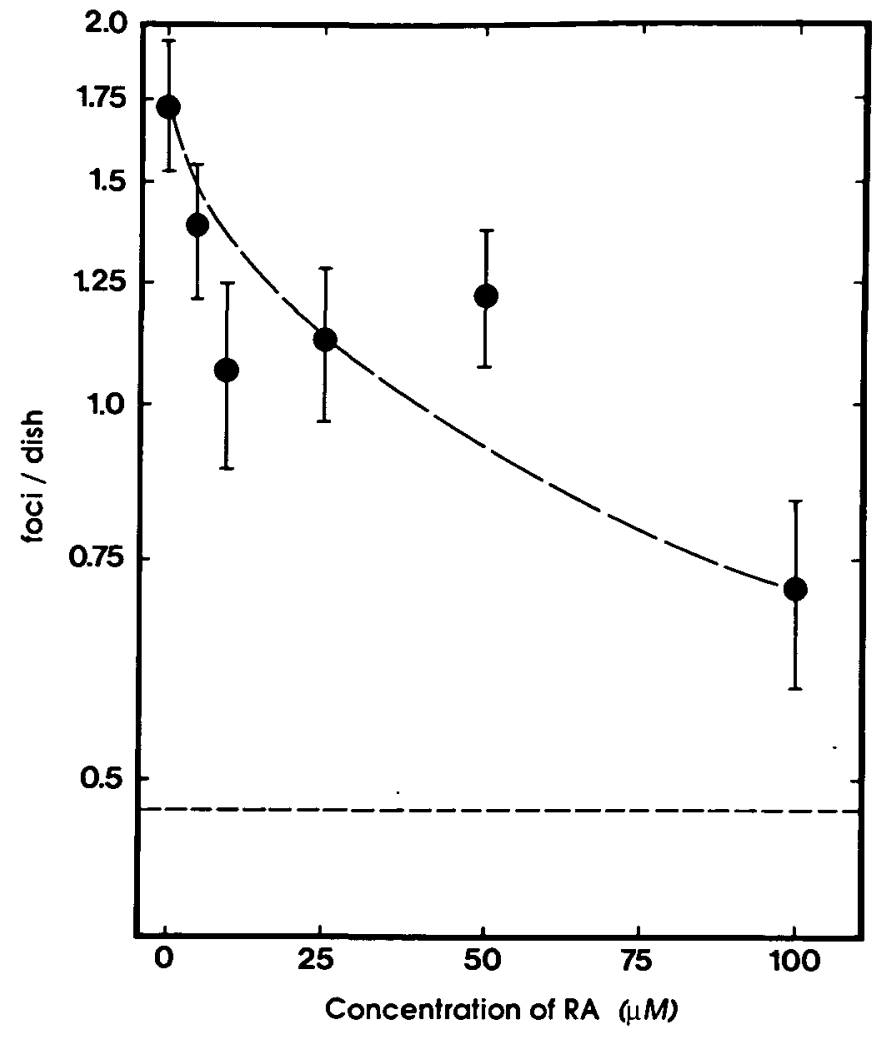

Fig. 3. Effect of RA on the fixation of initial transformational damage expressed in terms of the ultimate yield of transformed foci/dish in Balb/3T3 mouse fibroblasts irradiated with a dose of $5 \mathrm{~Gy}$ and held under confluent holding conditions during a $24 \mathrm{~h}$ post-irradiation recovery period. Dashed line: background transformation frequency of untreated controls. Data points were calculated from the pooled data of experiments II-VII as described elsewhere $(36,37)$. Error bars indicate one SD.

Table I. Number of dishes, transformation frequencies, and the percentage inhibition of the fixation of initial transformational damage by retinoic acid in X-irradiated Balb/3T3 mouse fibroblasts ${ }^{\mathrm{a}}$

\begin{tabular}{lllll}
\hline Treatment & $\begin{array}{l}\text { Concentration of } \\
\text { retinoic acid } \\
(\mu \mathrm{M})\end{array}$ & $\begin{array}{l}\text { Dishes without foci/ Foci per dish } \\
\text { total no. } \\
\text { of dishes }\end{array}$ & $\begin{array}{l}\text { Inhibition } \\
(\%)\end{array}$ \\
\hline control & - & $74 / 118$ & $0.47 \pm 0.07$ & - \\
5 Gy, i.s. - & $31 / 129$ & $1.42 \pm 0.15$ & - \\
5 Gy, d.s. 0 & $20 / 113$ & $1.73 \pm 0.20$ & 0 \\
5 Gy, d.s. 5 & $27 / 108$ & $1.39 \pm 0.17$ & 27.7 \\
5 Gy, d.s. 10 & $20 / 58$ & $1.06 \pm 0.18$ & 52.2 \\
5 Gy, d.s. 25 & $25 / 77$ & $1.12 \pm 0.16$ & 48.4 \\
5 Gy, d.s. 50 & $31 / 105$ & $1.22 \pm 0.15$ & 45.2 \\
5 Gy, d.s. 100 & $35 / 71$ & $0.71 \pm 0.12$ & 80.9 \\
\hline
\end{tabular}

${ }^{a}$ Cells in density-inhibited, confluent cultures were $X$-irradiated in the absence of RA and subcultured immediately after irradiation (i.s.) or after a post-irradiation confluent holding period of $24 \mathrm{~h}$ (d.s.) in the presence of various concentrations of RA. The fixation of initial transformational damage was expressed as the ultimate yield of foci per dish. The inhibition is calculated in terms of percentage inhibition of the transformation frequency observed in cells reincubated without RA, after subtracting the background transformation frequency observed in non-irradiated controls. ${ }^{b}$ Calculated from the number of dishes without foci as described elsewhere $(36,37)$.

dose-dependent fashion. This trend was evident in all six experiments, and is consistent with previous observations in human cells (38). 


\section{Effects of $R A$ on the fixation of initial transformational damage}

Figure 3 shows the inhibitory effect of RA on the fixation of initial transformational damage when it is present during the $24 \mathrm{~h}$ period of post-irradiation confluent holding. Table I shows this suppression in terms of percentage inhibition of the transformation frequency observed in cells reincubated without RA, after subtracting the background transformation frequency observed in non-irradiated controls. At $100 \mu \mathrm{M}, \mathrm{RA}$ suppressed the ultimate yield of transformed foci by $80 \%$. Table I also shows the total number of dishes from which these data were calculated.

A $24 \mathrm{~h}$ exposure of non-irradiated cells to RA did not affect the spontaneous formation of foci of transformed cells (data not shown). Hence, the suppression by RA of PLD repair leading to enhanced killing of non-cycling cells (Figure 2) is accompanied by a suppression of the fixation of initial transformational damage leading to a reduction in the induced frequency of transformation (Figure 3, Table I).

\section{Discussion}

Non-cytotoxic concentrations of RA (Figure 1) suppressed both recovery (Figure 2) and neoplastic transformation (Figure 3) when added to the medium during a $24 \mathrm{~h}$ post-irradiation confluent holding period. These observations suggest that RA is not only suppressing later events in neoplastic transformation involved with the expression of a transformed phenotype as reported by other investigators $(7-11,14-23)$, but also inhibits an early event. This may be caused by a relatively simple interaction such as a change in chromatin structure (39) or may involve more complex events, as for example an inhibition of sister chromatid exchanges which has been observed after exposure to cytotoxic drugs (40), or the inhibition of molecular error-prone mechanisms for the repair of X-ray-induced DNA damage (38).

The activity of such a mechanism in the fixation of initial transformational damage has been postulated based on the kinetics of transformation during confluent holding recovery in Xirradiated C3H 10T1/2 mouse cells (27). An inhibition of errorprone repair may be a causal molecular link between the inhibition of PLD repair by RA and the suppression of transformation. However, an alternative explanation for these results can be derived from the hypothesis that ionizing radiation causes two types of damage, namely potentially lethal and potentially transforming damage. RA could be causing decreased transformation, not by suppressing an error-prone repair mechanism but by decreasing the number of cells with transforming damage that escape the cytotoxic effects of potentially lethal damage.

The findings of this study are of particular interest as regards a possible application of retinoids in radiation therapy: they may not only allow a selective enhancement in the inactivation of certain irradiated cancer cells as compared to normal cells (38), but also reduce the risk of secondary tumors (41) in successfully treated patients. On the other hand, the toxic side-effects of RA (4-6) may limit the use of this drug as modifier for radiotherapy, since effective concentrations in the present study were well above physiological levels. Hypervitaminosis A also prohibited the use of clinically effective doses of RA for the systemic treatment of dermatological disorders (42-45). However, it may be possible to identify retinoids with a better therapeutic index for clinical use as a biological response modifier for radiation therapy, as has been successfully done in the search for effective retinoids in dermatology (46).

\section{Acknowledgements}

We thank Ling-Nah Su for her excellent assistance with transformation experiments VI and VII. This work was supported by Research grant CA-47542 and Center Grant ES-00002 from the US National Institute of Health. H.P.R. was recipient of a Scholarship from the Swiss National Science Foundation.

\section{References}

1. Saffiotti,U., Montesano,R., Sellakumar,A.R. and Borg,S.A. (1967) Experimental cancer of the lung. Inhibition by vitamin $A$ of the induction of tracheobronchial squamous metaplasia and squamous cell tumors. Cancer, $20,857-864$.

2. Bollag,W. (1972) Prophylaxis of chemically induced benign and malignant epithelial tumors by vitamin A acid (retinoic acid). Eur. J. Cancer, 8, $689-693$.

3. Bollag,W. (1974) Therapeutic effects of an aromatic retinoic acid analog on chemically induced skin papillomas and carcinomas of mice. Eur. J. Cancer, $10,731-737$.

4. Bollag, W. and Hartmann,H.R. (1983) Prevention and therapy of cancer with retinoids in animals and man. Cancer Surv., 2, 293-314.

5. Orfanos,C.E., Ehlert,R. and Gollnick,H. (1987) The retinoids. A review of their clinical pharmacology and therapeutic use. Drugs, 34, 459-503.

6. Lippman,S.M. and Meyskens,F.L. (1988) Retinoids as anticarcinogens. In Nutrition, Growth, and Cancer. Alan R.Liss, New York, pp. 229-244.

7. Merriman,R.L. and Bertram,J.S. (1979) Reversible inhibition by retinoids of 3-methylcholanthrene (MCA) induced neoplastic transformation in C3H/10T1/2 clone 8 cells. Cancer Res., 39, 1661-1666.

8. Umezawa,K., Fukamachi,H., Hirakawa,T., Takayama,S., Matsushima,T. and Sugimura,T. (1979) Inhibition of chemical transformation of hamster embryo cells by retinoids. Toxicol. Lett., 4, 87-92.

9. Maas, M.J., Nettesheim,P., Beeman,D.K and Barrett,J.C. (1984) Inhibition of transformation of primary rat tracheal epithelial cells by retinoic acid. Cancer Res., 44, 5688-5691.

10. Harisidiadis,L., Miller,R.C., Hall,E.J. and Borek,C. (1978) Vitamin A analogue inhibits radiation-induced oncogenic transformation. Nature, 274, $486-487$.

11. Kennedy,A.R. (1984) Prevention of radiation transformation in vitro. In Prasad (ed.), Vitamins, Nutrition and Cancer. Karger, Basel, pp. 166-179.

12. Garte,S.J., Currie,D., Motz,J. and Troll,W. (1988) Retinoic acid inhibits transformation of NIH 3 T3 cells by the human H-ras oncogenes. Proc. Am. Assoc. Cancer Res., 29, 140.

13. Little,J.B., Nagasawa,H. and Kennedy,A.R. (1979) DNA repair and malignant transformation: effect of X-irradiation, 12-O-tetradecanoyl-phorbol-13-acetate, and protease inhibitors on transformation and sister-chromatid exchanges in mouse 10T1/2 cells. Radiat. Res., 79, 241-255.

14. Roberts,A.B., Roche,N.S. and Sporn,M.B. (1985) Selective inhibition of the anchorage independent growth of myc-transfected fibroblasts by retinoic acid. Nature, 315, $237-239$.

15. Mordan,L.J. and Bertram,J.S. (1983) Retinoid effects on cell-cell interaction and growth characteristics of normal and carcinogen-treated C3H/10T1/2 cells. Cancer Res., 43, 567-571.

16. Fitzgerald,J.D., Barrett,J.C. and Nettesheim,P. (1986) Changing responsiveness of rat tracheal epithelial cells at different stages of neoplastic transformation. Carcinogenesis, 7, 1715-1721.

17. Bertram,J.S. (1980) Structure-activity relationships among various retinoids and their ability to inhibit neoplastic transformation and to increase cell adhesion in the C3H/10T1/2 Cl 8 cell line. Cancer Res., 40, 3141-3146.

18. Martner,J.E. and Bertram,J.S. (1986) Enhanced protein phosphorylation of carcinogen-initiated 10T $1 / 2$ cells accompanies their neoplastic transformation. Carcinogenesis, 7, $1301-1308$.

19. Mordan,L.J., Hui,S.W. and Bertram,J.S. (1984) Modulation by retinoids of microfilament bundle formation in $\mathrm{C} 3 \mathrm{H} / 10 \mathrm{~T}^{1 / 2}$ cells. J. Cell. Biochem., 24, 15-25.

20. Theile,C.J., Reynolds,C.P. and Israel,M.A. (1985) Decreased expression of $\mathrm{N}$-myc preceeds retinoic acid-induced morphological differentiation of human neuroblastoma. Nature, 313, 404-406.

21. Jetten,A.M. (1980) Retinoids specifically enhance the number of epithelial growth factor receptors. Nature, 284, 626-629.

22. Lippmann,S.M., Kessler,J.F. and Meyskens,F.L. (1987) Retinoids as preventive and therapeutic anticancer agents (part I). Cancer Clin. Treat. Rep., 71, $391-405$.

23. Mordan,J.L. (1989) Inhibition by retinoids of platelet growth factor-dependent 
stimulation of DNA synthesis and cell division in density-arrested C3H10T1/2 fibroblasts. Cancer Res., 49, 906-909.

24. Kano, Y., Grosovsky,A.J. and Little,J.B. (1987) Interrelationships among Xray-induced anchorage independence, mutagenesis and chromosomal rearrangements in human diploid fibroblasts. Int. J. Cancer, 40, 64-68.

25. Little,J.B. (1969) Repair of sub-lethal and potentially lethal radiation damage in plateau phase cultures of human cells. Nature, 224, 804-806.

26. Hahn,G.M. and Little,J.B. (1972) Plateau-phase cultures of human cells: An in vitro system for human cancer. Curr. Top. Radiat. Res. Quart. 8, 39-83.

27. Terzhagi,M. and Little,J.B. (1975) Repair of potentially lethal radiation damage in mammalian cells is associated with enhancement of malignant transformation. Nature, 253, 548-549.

28. Nagasawa,H. and Little,J.B. (1981) Induction of chromosome aberrations and sister chromatid exchanges by X-rays in density-inhibited cultures and mouse 10T1/2 cells. Radiat. Res., 87, 538-551.

29. Kano, Y. and Little,J.B. (1984) Persistence of X-ray induced chromosomal rearrangements in long term cultures of human diploid fibroblasts. Cancer Res., 44, 3706-3711.

30. Weichselbaum,R.R., Nove,J. and Little,J.B. (1978) Deficient recovery from potentially lethal radiation damage in Ataxia telangiectasia and Xeroderma pigmentosum. Nature, 271, 261-262.

31. Utsumi,H. and Sasaki,M.S. (1984) Deficient repair of potentially lethal damage in actively growing Ataxia telagiectasia cells. Radiat. Res., 97, 407-413.

32. Grosovsky,A.J. and Little,J.B. (1983) Influence of confluent holding time on UV light mutagenesis in human diploid fibroblasts. Mutat. Res., 110 $401-412$.

33. Little,J.B. (1979) Quantitative studies of radiation transformation with the A31-11 mouse Balb/3T3 cell line. Cancer Res., 39, 1474-1480.

34. Kakunaga, T. (1973) A quantitative system for assay of malignant transformation by chemical carcinogens using a clone derived from Balb/3T3. Int. J. Cancer, 12, 463-473.

35. Kennedy,A.R., Fox,M., Murphy,G. and Little,J.B. (1980) Relationship between $\mathrm{X}$-ray exposure and malignant transformation in $\mathrm{C} 3 \mathrm{H} 10 \mathrm{~T} 1 / 2$ cells. Proc. Natl. Acad. Sci. USA, 77, 7262-7266.

36. Han,A. and Elkind,M.M. (1979) Transformation of mouse C3H/10T1/2 cells by single and fractionated doses of $\mathrm{X}$-rays and fission spectrum neutrons. Cancer Res., 39, 123-130.

37. Balcer-Kubiczek,E.K., Harrison,G.H. and Thompson,B.W. (1987) Repair time of oncogenic transformation in $\mathrm{C} 3 \mathrm{H} / 10 \mathrm{~T} 1 / 2$ cells subjected to protracted X-irradiation. Int. J. Radiat. Biol., 51, 219-226.

38. Rutz,H.P. and Litte,J.B. (1989) Modification of radiosensitivity and recovery from X-ray damage in vitro by retinoic acid. Int. J. Radiat. Oncol. Biol. Phys., $16,1285-1288$.

39. Porter,S.B., Ong,D.E. and Chytil,F. (1986) Vitamin A status affects chromatin structure. Int. J. Vit. Nutr. Res., 56, 11-20.

40. Huang,C.C., Hseuh, J.L., Chen,H.H. and Butt, T.R. (1982) Retinol (vitamin A) inhibits sister chromatid exchange and cell-cycle delay induced by cyclophosphamide and aflatoxin $B_{1}$ in Chinese hamster V79 cells. Carcinogenesis, 3, 1-5.

41. Li,F.P. (1985) Second cancers. In DeVita,V.T., Hellman,S. and Rosenberg,S.A. (eds), Principles and Practice of Oncology, 2nd ed. J.B.Lippincott, Philadelphia, pp. 2040-2049.

42. Ott,D.B. and Lachance,P.A. (1979) Retinoic acid-a review. Am. J. Clin. Nutr., 32, 2522-2531.

43. Haneke,E. and Bauer, R. (1984) Lokale und systemische Therapie mit alltrans Retinsäure in der Dermatologie. In Bauer,B. and Gollnik,H. (eds) Retinoide in der Praxis Grosse, Berlin, pp. 66-73.

44. Lucek, R.W. and Colburn,W.A. (1985) Clinical pharmacokinetic of the retinoids. Clin. Pharmacokin., 10, 38-62.

45. Teelmann,K. (1989) Retinoids: toxicology and teratogenicity to date. Pharmacol. Ther., 40, 29-43.

46. Bollag,W. (1983) The development of retinoids in experimental and clinical oncology and dermatology. J. Am. Acad. Dermatol., 9, 797-805.

Received on April 11, 1989; revised on August 17, 1989; accepted on September 14,1989 